\title{
Agricultura familiar e segurança alimentar na Comunidade Quilombola África, Abaetetuba (PA)
}

Os remanescentes de comunidades quilombolas são grupos étnico-raciais com trajetórias históricas próprias, dotados de relações territoriais específicas, com presunção de ancestralidade negra relacionada com a resistência à opressão histórica sofrida. Este estudo objetivou conhecer o modo pelo qual a comunidade quilombola África, no município de Abaetetuba (PA), relaciona-se com a natureza, bem como averiguar se a prática da agricultura familiar está sendo eficiente na manutenção da segurança alimentar dessa população. Para a coleta de dados, foram adotadas entrevistas semiestruturadas e listagem livre. Os resultados evidenciaram alteraç̃̃es no modo vida da comunidade quilombola África, com maior apego dos sujeitos ao modo de vida urbano. Sendo que, a agricultura familiar não é, mas, o elemento responsável pela manutenção da segurança alimentar dessa população.

Palavras-chave: Amazônia; Povos tradicionais; Organização social.

\section{Family Farming and Food Security in the Quilombola Community Africa, Abaetetuba (PA)}

The remnants of quilombola communities are ethnic-racial groups with their own historical trajectories, endowed with specific territorial relations, with presumption of black ancestry related to the resistance to the historical oppression suffered. This study aimed to understand the way in which the quilombola community in Africa, in the municipality of Abaetetuba (PA), relates to nature, as well as to investigate if the practice of family farming is being efficient in maintaining the food security of this population. For data collection, semi-structured interviews and free listing were adopted. The results showed changes in the way of life of the quilombola community in Africa, with greater attachment of the subjects to the urban way of life. Since family farming is not the element responsible for maintaining the food security of this population.

Keywords: Amazon; Traditional peoples; Social organization.

Topic: Desenvolvimento, Sustentabilidade e Meio Ambiente

Reviewed anonymously in the process of blind peer.

\section{Priscila Fonseca Ferreira}

Universidade Federal do Pará, Brasil

http://lattes.cnpq.br/0501849255126844

priscilafonseca.13@hotmail.com

Altem Nascimento Pontes

Universidade Federal do Pará, Brasil

http://lattes.cnpq.br/5993352890364998

http://orcid.org/0000-0002-9001-4603

altempontes@hotmail.com

Manoel Tavares de Paula

Universidade Federal do Pará, Brasil

http://lattes.cnpq.br/6820319111894773

dpaulamt@hotmail.com
Received: 17/07/2018

Approved: $29 / 10 / 2018$
Referencing this:

FERREIRA, P. F.; PONTES, A. N.; PAULA, M. T.. Agricultura familiar e segurança alimentar na Comunidade Quilombola África, Abaetetuba (PA). Natural Resources, v.8, n.2, p.60-65, 2018. DOI: http://doi.org/10.6008/CBPC2237-9290.2018.002.0007 


\section{INTRODUÇÃO}

Os remanescentes de comunidades quilombolas são grupos étnico-raciais, segundo critérios de autodefinição. Apresentam trajetória histórica própria, dotados de relações territoriais específicas, com presunção de ancestralidade negra relacionada com a resistência à opressão. São organizados na lógica da economia agroextrativista e no uso de recursos naturais (BRASIL, 2012; ARAUJO et al., 2017). A maioria dos quilombos sobrevivem da extração vegetal e animal de baixa intensidade, seja para o próprio consumo ou para obtenção de renda (CARVALHO et al., 2014).

De acordo com o artigo 68 da Constituição Federal de 1988, as comunidades quilombolas são unidades político-administrativas, o que assegura a essas pessoas o direito as suas terras (ARAUJO et al., 2017). No entanto, esse benefício não resolve a pobreza e a falta de recursos, sociais e econômicos. A maioria das comunidades quilombolas encontra-se em condições extremas de pobreza e marginalizadas aos interesses da sociedade (TEIXEIRA et al., 2011).

De acordo com Silva et al. (2016), todas as comunidades quilombolas do país, apresentam problemas no acesso ao direito à alimentação ao longo de toda a sua história. Estudos recentes mostram que cerca de $42 \%$ dessa população está em situação de insegurança alimentar, sendo esse percentual ainda maior na região norte (62\%) (PINTO et al., 2014). De acordo com Carvalho et al. (2014) a Segurança Alimentar e Nutricional (SAN) está relacionada a condições de vida e nutricional adequadas, sendo a pobreza a principal causa dessa insegurança. Neste cenário, a agricultura familiar tem contribuído consideravelmente para a sobrevivência de muitas famílias (SILVA et al., 2016).

Desde o período colonial, durante a escravidão, a agricultura sempre foi uma atividade desenvolvida pelos negros (CARVALHO et al., 2014). Nesta prática, observam-se técnicas e manejos da agricultura africana, trazida ao país pelos negros, bem como, técnicas usadas pelos índios (FIDELIS, 2006). De acordo com Fidelis et al. (2013), a agricultura é para as comunidades quilombolas a base para reprodução e segurança alimentar do núcleo familiar.

O Pará é um dos estados que possui o maior número de comunidades quilombolas remanescentes, ficando atrás apenas, da Bahia e Maranhão (HAGE et al., 2013). Na região, atualmente, cerca de 375 comunidades se autorreconhecem como quilombolas, sendo 73, cerca de 18.300 pessoas, tituladas pelo Instituto de Terras do Pará (ITERPA, 2018). Dentre os municípios, destaca-se Abaetetuba, que com seus $1610 \mathrm{~km}^{2}$ apresenta cerca de $9 \%$ do seu território titulado a este tipo de comunidade (ITERPA, 2018; BRASIL, 2018).

O município de Abaetetuba tem passado por inúmeras transformações desde a sua criação em 1880, de uma economia rural e primária, o município passou a ter nos últimos anos as suas relações de produção baseadas no setor secundário (indústria) e terciário (serviços) (QUARESMA et al., 2016). Estas transformações são refletidas nas sociedades urbana e rural, bem como nas comunidades quilombolas, que tem se mostrado resistentes em manter suas tradições culturais, religiosas e o cuidado com a terra (BRASIL, 2013). Com isso, este estudo objetivou conhecer o modo pelo qual a comunidade quilombola África, no município de 
Abaetetuba, Pará, se relaciona com a natureza, bem como averiguar se a prática da agricultura familiar está sendo eficiente na manutenção da segurança alimentar dessa população.

\section{MATERIAIS E MÉTODOS}

A comunidade quilombola África está localizada nas coordenadas $1^{\circ} 73^{\prime}$ a $1^{\circ} 43^{\prime} \mathrm{S}$ e $48^{\circ} 59^{\prime}$ a $48^{\circ} 35^{\prime} \mathrm{W}$, no município de Abaetetuba, na região nordeste paraense. A população no município é de cerca de 141.000 , das quais $59 \%$ vivem na cidade e $41 \%$ na zona rural (IBGE, 2010). A Floresta Densa de Terra Firme, que predominava na região, foi substituída, quase em sua totalidade, por florestas secundárias, formando um mosaico com os cultivos agrícolas (MATA et al., 2011; FAPESPA, 2016).

A comunidade quilombola África apresenta bastante expressão, participando dos movimentos da cultura quilombola, seja na divulgação de seus produtos artesanais em feiras municipais ou estaduais, como também na criação de projetos como 'Filhos do Quilombo' que visa à manutenção da identidade cultural. Para realizar a coleta de dados, o líder da comunidade concedeu uma autorização para o estudo, assinando o Termo de Anuência Prévia (TAP).

Devido à impossibilidade de se identificar de imediato os informantes, empregou-se para a amostragem o método 'bola de neve' (snow-ball) (VINUTO, 2014). Por meio desse método, o líder comunitário selecionou um determinado grupo de pessoas que detinham o conhecimento esperado e que após serem entrevistadas, indicavam outras pessoas, até atingir-se um contingente amostral representativo (VINUTO, 2014).

O estudo se desenvolveu através de entrevistas semiestruturadas, com questões previamente estabelecidas e listagem livre. $O$ objetivo da metodologia é estimular o informante a falar abertamente, sem as limitações criadas por um questionário (ALBUQUERQUE et al., 2010). A listagem livre foi utilizada para identificar os alimentos mais consumidos e comercializados pelas famílias. De acordo com Santos et al. (2012), na listagem livre, os produtos primeiramente citados, e com maior frequência de citações, são os que têm maior importância cultural.

As questões norteadoras estavam relacionadas aos produtos cultivados (consumo e comércio), criação de animais (consumo e comércio), alimentos consumidos e os modos de produção. Os dados foram coletados no período de março a abril de 2014 e foram entrevistadas 20 das 23 famílias que vivem na comunidade quilombola África.

\section{DISCUSSÃO TEÓRICA}

Os resultados demonstram alterações no modo vida da comunidade quilombola África, com maior apego dos sujeitos ao modo de vida urbano. A agricultura familiar não é mais o elemento responsável pela manutenção da segurança alimentar dessa população. Observou-se que $100 \%$ dos informantes necessitam comprar alimentos em municípios próximos. Cerca de $40 \%$ dos entrevistados afirmaram fazer roça para subsistência, 35\% relataram que as necessidades são supridas com a criação de animais, $30 \%$ com a pesca e $15 \%$ com a caça. 
A compra de suprimentos em outras localidades representa a principal forma de aquisição de alimentos pelos moradores, enquanto o plantio, a criação de animais, a pesca e a caça surgiram como fontes complementares. Os principais produtos provenientes de outros municípios são: alimentos enlatados (conserva e sardinha), embutidos (mortadela e salsicha), carnes (gado bovino e peixes) e principalmente 'complementos', tais como feijão, arroz e macarrão.

No contexto da comunidade África, a agricultura familiar surge como elemento secundário, e é responsável apenas por uma parte da complementação alimentar dessa população. Os principais produtos cultivados são: milho, hortaliças, pimenta, frutas e principalmente a mandioca. Da mandioca, os moradores fazem a farinha, que além de ser consumida, é vendida nas feiras do município e arredores.

Em estudo realizado em comunidades quilombolas no estado de São Paulo, Navas et al. (2016) verificou que, apesar das transformações na região, as práticas agrícolas ainda representam o elemento essencial para a reprodução das famílias, fornecendo alimento, renda e conservação da sociodiversidade. Os Navas et al. (2016) ainda citam que não há ou são incipientes os incentivos públicos para a produção agrícola na região, o que não justifica a permanência das comunidades estudadas nestas atividades. Ou seja, mesmo sem incentivos governamentais, as comunidades quilombolas do estado de São Paulo permanecem em seu modo de vida tradicional. Considerando estes fatos, é possível que, outros fatores que não a falta de incentivos, estejam atuando na perda da cultura da prática agrícola na comunidade África.

Estudos vêm relatando mudanças na alimentação de populações quilombolas, com uma menor produção para autoconsumo e com predominância de uma dieta mais ocidentalizada com base em produtos industrializados (UCHOA et al., 2014; NAVAS, et al., 2015). Os resultados encontrados na comunidade África, corroboram para uma hipótese de transição alimentar. Pollan (2008) comenta sobre a relação da "dieta do supermercado" com as patologias ocidentais (doenças cardiovasculares, câncer, hipertensão, diabetes, AVCs e obesidade), o que seria extremamente danoso para as populações quilombolas, uma vez que, geralmente, elas se encontram distantes dos serviços básicos de saúde.

É por meio da terra que são originados os alimentos, mas também é nela que se desenvolve costumes e hábitos que norteiam a identidade e identificação de um grupo social. Navas et al. (2016), estudando os quilombolas do estado de São Paulo, verificaram que, os alimentos cultivados apresentaram maior valor cultural do que propriamente alimentar, com produtos cultivados especialmente para ocasiões especiais e até mesmo para festas religiosas. Na comunidade África, essa relação cultural é observada apenas com a mandioca. Maranhão et al. (2015) identificou uma vasta lista de usos da mandioca, onde além de complementar a alimentação e economia das famílias, também se mostra importante na cultura dessas pessoas.

A criação de galinhas e patos ocorre sem fins econômicos, e é desenvolvida para suprir a falta da carne de gado bovino. A caça e a pesca, mesmo que em menores proporções, são boas fontes alimentícias para a população da comunidade África. De acordo com os informantes, na caça são encontrados principalmente a cutia, paca, tatu e a mucura, enquanto na pesca, encontram-se peixes como o acará, aracu, traíra, tucunaré, dentre outros. Em estudos realizados na comunidade quilombola do Abacatal, no município 
de Ananindeua, animais domésticos (pato, galinha, porco) foram encontrados em mais de $80 \%$ das residências (FREITAS et al., 2010; ARAUJO, 2017).

Embora os moradores do Abacatal tenham relatado que a criação dos animais visa atender o consumo familiar, esses valores são muito superiores aos registrados a partir dos relatos dos moradores da comunidade África, onde apenas cerca de 35\% dos moradores citaram criar animais para o consumo próprio. Essas análises indicam uma acentuada perda das tradições na área de estudo.

Observou-se ainda que o modo de vida baseada na lógica da economia agroextrativista e no uso de recursos naturais, que historicamente deveria ser praticado por este tipo de comunidade, na Comunidade África, está sendo substituído por um modo de vida ocidentalizado. Esses resultados corroboram com Ferreira et al. (2016), que constatou, também na comunidade África, desgaste do conhecimento tradicional, bem como o enfraquecimento das relações com os recursos naturais, com perdas na viabilidade econômica e sustentabilidade.

Esses dados contrariam as análises feitas por Nahum et al. (2013), que afirma que o Programa Raízes e o Plano Estadual de Políticas de Promoção da Igualdade Racial do Pará (PEPPIR) têm promovido o ordenamento territorial das comunidades remanescentes de quilombo, e assim a valorização das tradições que se manifestam através de seu território.

As atividades tradicionais como os roçados estão perdendo drasticamente espaço para a compra de alimentos, isso não significa apenas uma mudança nos hábitos alimentares, mas também uma perda significativa da cultura. Para Carmo et al. (2016), resultados como estes são preocupantes, por demonstrar a perda da cultura de subsistência, uma prática que acompanhou essas comunidades ao longo do tempo, e as mantiveram isoladas da sociedade mais abrangentes. Portanto, é necessário e urgente que haja investimentos que valorizem estas atividades, para que as mesmas não venham a se perder com o tempo.

As populações quilombolas acumulam um importante saber tradicional sobre a produção de alimentos, formas de cultivo e criação mais adaptadas às condições ecológicas. Ações de preservação da relação do homem quilombola com a natureza, bem como de reconhecimento pelos demais membros da sociedade são fundamentais. Além de garantir a segurança alimentar dessas populações, o entendimento destas relações pode auxiliar na conservação do meio ambiente.

\section{CONCLUSÕES}

É necessária uma reflexão sobre a realidade quilombola da comunidade África, com aplicação de políticas públicas que sejam adequadas, que tragam incentivos e resultem em melhorias sociais e econômicas. Afinal, a permanência do homem no campo é um importante meio de combate à pobreza nas grandes cidades.

Embora a principal fonte de alimento da comunidade quilombola África seja os comércios locais, está ainda mantém uma relação com a terra, a qual serve de complemento na alimentação das famílias. A fim de evitar que as tradições dessa comunidade sejam perdidas, é preciso o incentivo de instituições, governamentais ou não governamentais, que promovam a valorização da agricultura familiar de subsistência. 


\section{REFERÊNCIAS}

ALBUQUERQUE, U. P.; LUCENA, R. F. P.; ALENCAR, N. L.. Métodos e técnicas para coleta de dados etnobiológicos. In: ALBUQUERQUE, U. P.; LUCENA, R. P.; CUNHA, L. V. F. C.. Métodos e técnicas na pesquisa etnobiológica e etnoecológica. Recife: NUPEEA, 2010. p.47-49.

ARAUJO, A. S.; ANJOS, D. R.; SILVA, R. S.; SANTOS, M. A. S; MARTINS; C. M.; ALMEIDA, C.. Análise socioeconômica de agricultores da comunidade quilombola do Abacatal, Ananindeua, estado do Pará, Brasil. Biota Amazônia, v.7, n.1, p.30-37, 2017. DOI: http://doi.org/10.18561/2179$\underline{5746 / \text { biotaamazonia }}$

BRASIL. Ministério da Cultura. Quilombolas do Brasil. Brasília: MC, 2013.

BRASIL. Ministério do Desenvolvimento Agrário Sistema de informações territoriais. Brasília: MDA, 2018.

BRASIL. Programa Brasil Quilombola. Brasília: SPPIR, 2012.

CARMO, M. S.; COMITRE, V.; BORSATTO, R. S.

Sustentabilidade nos quilombos João Surá e Jaó. Espacios, v.37, n.17, p.15, 2016.

CARVALHO, A. S.; SILVA, D. O.. Perspectivas de segurança alimentar e nutricional no Quilombo de Tijuaçu, Brasil: a produção da agricultura familiar para a alimentação escolar. Interface, Botucatu, v.18, n.50, p.521-532, 2014. DOI: http://doi.org/10.1590/1807-57622013.0804

FAPESPA. Fundação Amazônia de Amparo a Estudos e Pesquisas. Estatísticas Municipais Paraenses: Abaetetuba. Belém: FAPESPA, 2016.

FERREIRA, P. F.; MARTINS, A. C. C. T.; PAULA, M. T.; LUCAS, F. C. A.; GONCALVES, J. P.; MIRANDA, T. G.; SIMÕES, P. H. O.. Indicadores de sustentabilidade na comunidade quilombola África, município de Abaetetuba, Pará, Brasil. Espacios, v.38, n.8, p.9, 2017.

FIDELIS, L. M.; BERGAMASCO, S. M. A.. Quilombos e a agroecologia: a agricultura tradicional como estratégia de resistência da comunidade Quilombola João Surá. Revista Eletrônica da Associação dos Geógrafos Brasileiros, Lagoas, v.10, n.18, 2013.

FREITAS, G. G.; COSTA, R. L. G. M.; VENTURIM, N.; COSTA, K. L.. Etnosilvicultura de quintais agroflorestais da comunidade quilombola de Abacatal (PA). Brasília: Embrapa, 2010.

HAGE, S. A. M.; CARDOSO, M. B. C.. Educação do campo na Amazônia Interfaces com a educação quilombola. Retratos da Escola, v.7, n.13, p.425-438, 2013.

IBGE. Instituto Brasileiro de Geografia e Estatística. Censo Demográfico 2010. Rio de Janeiro: IBGE, 2010. ITERPA. Instituto de Terras do Pará. Quilombolas. Belém: ITERPA, 2018.
MARANHÃO, R. F. A.; BASTOS, S. R.; MARCHI, M. M.. Cultura e sociedade no sistema culinário da mandioca no Brasil. Sociais e Humanas, v.28, n.2, p.54-68, 2015.

MATA, T. C.; AZEVEDO, H. P.; COSTA, M. N.; BEZERRA, R. M.; SOUSA, R. P.; COSTA, A. P.. Açaí com mel: uma experiência de pesquisa: desenvolvimento em comunidades ribeirinhas na Amazônia Paraense. Cadernos de Agroecologia, v.6, n.2, 2011.

NAHUM, J. S.; OLIVEIRA, J. B.. Políticas de estado para comunidades remanescentes de quilombo na Amazônia Paraense. ACTA Geográfica, v.7, n.14, p.7-23, 2013. DOI: http://doi.org/10.5654/actageo2013.0714.0001

NAVAS, R.; KANIKADAN, A. Y.; SANTOS, K. M. P.; GARAVELLO, M. E. P. E.. Transição alimentar em comunidade quilombola no litoral sul de São Paulo/Brasil. NERA, v.18, p.138-155, 2015.

PINTO, A. R.; BORGES, J. C.; NOVO, M. P.; PIRES, P. S.. Quilombos do Brasil: segurança alimentar e nutricional em territórios titulados. Cadernos de Estudos Desenvolvimento Social em Debate, Brasília, 2014.

POLLAN, M.. Em defesa da comida: um manifesto. Rio de Janeiro: Intrínseca, 2008.

QUARESMA, M.; SOMBRA, M.; LEITE, A. Periodização econômica de Abaetetuba (PA) a partir de sua configuração espacial. PerCursos, v.16, n.32, p.143-168, 2015. DOI: http://doi.org/10.5965/1984724616322015143

SANTOS, K. M. P. S.; GARAVELLO, M. E. P. E.. Segurança alimentar em comunidades quilombolas de São Paulo. Segurança Alimentar e Nutricional, Campinas, v.23, n.1, p.786-794, 2016

SANTOS, R. S.; COELHO-FERREIRA, M. Estudo etnobotânico de Mauritia flexuosa L. f. (Arecaceae) em comunidades ribeirinhas do Município de Abaetetuba, Pará, Brasil. Acta Amazônica, v.42, n.1, p.1-10, 2012.

SILVA, W. A.; MIRA, F. Agricultura familiar e segurança alimentar em comunidades quilombolas do semiárido alagoano, Geosertões, v.1, n.2, p.60-79, 2016.

TEIXEIRA, M. G.; BRAGA, J. S.; CESAR, S. F.; KIPERSTOK, A.. Artesanato e desenvolvimento local: o caso da comunidade quilombola de Giral Grande, Bahia. Interações, v.12, n.2, 2011.

UCHOA, J. K.; AGUIAR, W. R.; TAKANASHI, S. Y. L.; GALVAO, E. F. C.. O perfil nutricional de quilombolas de comunidades de áreas de várzea e planalto e sua relação com hipertrigliceridemia hipercolesterolemia, no município de Santarém-PA. Em Foco, v.21, n.22, 2014.

VINUTO, J.. A amostragem em bola de neve na pesquisa qualitativa: um debate em aberto. Temáticas, v.22, n.44, p.203-220, 2014

A CBPC - Companhia Brasileira de Produção Científica (CNPJ: 11.221.422/0001-03) detém os direitos materiais desta publicação. Os direitos referem-se à publicação do trabalho em qualquer parte do mundo, incluindo os direitos às renovações, expansões e disseminações da contribuição, bem como outros direitos subsidiários. Todos os trabalhos publicados eletronicamente poderão posteriormente ser publicados em coletâneas impressas sob coordenação da Sustenere Publishing, da Companhia Brasileira de Produção Científica e seus parceiros autorizados. Os (as) autores (as) preservam os direitos autorais, mas não têm permissão para a publicação da contribuição em outro meio, impresso ou digital, em português ou em tradução. 